\title{
KEUNGGULAN PRODUK ICONIC ISOLATING SARUNG SAMARINDA
}

\author{
Herning Indriastuti ${ }^{1 *}$, Syarifah Hudayah ${ }^{1}$ \\ ${ }^{1}$ Fakultas Ekonomi dan Bisnis , Universitas Mulawarman Indonesia \\ *herning.indriastuti@feb.unmul.ac.id
}

\begin{abstract}
Abtract
This research examines whether marketing innovativeness (MI) enhance marketing performance (MP) and tries to solve the problems of research gap between marketing innovativeness and marketing performance. The sample are SME's Saroong Samarinda indutries in East Borneo, Indonesia. The total data that can be further analysed are 235 respondents. Data analysing uses Structural Equation Modelling. The result showes that : 1) small companies in these market segments based regiocentric is likely have better marketing performance when they have the iconiq isolating advantages, 2) the marketing innovativeness has significant effect on iconiq isolating advantages, 3) iconiq isolating advantages is a mediator in the correlation of marketing innovativeness and marketing performance
\end{abstract}

Keywords: Marketing Innovation, Isolating Iconic Product, Marketing Performance

\section{PENDAHULUAN}

Sarung Samarinda merupakan salah satu produk ikonik dan identitas khas Kalimantan Timur. Keberadaan Sarung Samarinda tidak lepas dari peran pendatang dari suku Wajo-Bugis yang merupakan cikal bakal sebagai pioner pembuat sarung tenun khas Samarinda, dimana pembuatan sarung ini masih menggunakan alat manual atau gedogan. Dalam proses menenun dengan gedogan membutuhkan waktu yang lama karena gedogan merupakan alat tradisional yang dioperasikan secara manual, sehingga pembuatan sarung ini sulit untuk di tiru, kecuali pembuatan sarung dengan cara cetak atau printing. Ini merupakan permasalahan utama yang menjadi ancaman bagi kelangsungan Sarung Samarinda.

Sarung Samarinda secara motif tidak terlepas dari proses akulturatif beberapa budaya yaitu kebudayaan dari pendatang suku Wajo-Bugis serta budaya Kutai dan Dayak. Perpaduan dua budaya ini menghasilkan lebih dari 30 motif dan motif yang diperuntukkan untuk perempuan biasanya motif pucuk rebung dan Sabbi, juga ada motif yang dipengaruhi oleh motif budaya Dayak yang biasanya bermotif Flora-Fauna. Seluruh proses penenunan biasanya dikerjakan oleh para wanita, karena menenun hanyalah merupakan kerja sambilan. Permasalahan lainnya adalah kurangnya regenerasi pada proses penenunan karena dianggap sebagai pengisi waktu, pembuatan kain tenun memakan waktu lama, perlu ketelatenan dan ketelitian, ini yang sudah sulit di dapat pada anak muda sekarang, selain itu juga karena kurangnya inovasi baik itu inovasi produk maupun inovasi pemasaran. Untuk mengetahui gap yang terjadi, beberapa studi menemukan bahwa inovasi pemasaran sangat berpangaruh signifikan terhadap kinerja pemasaran (Al-Zyadaat dkk., 2012, Karabulut, 2015.,Moreira $d k k$., 2012). Di sisi lain terdapat penelitian yang mengatakan bahwa inovasi pemasaran tidak berpengaruh signifikan terhadap kinerja pemasaran 
(Atalaya, dkk 2013., Darmanto, dkk 2014., Cillo, dkk 2010., Hoonsopon dan Ruenrom, 2012., Rosli dan Sidek, 2013., AtuaheneGima, dkk 2006).

Mekanisme isolating telah dikembangkan dalam literatur sebagai konstruksi intelektual untuk menjelaskan hambatan kompetitif di tingkat perusahaan individual. Mekanisme isolating didefinisikan sebagai fitur istimewa dari manajemen perusahaan untuk menciptakan hambatan untuk menghalangi pesaing meniru sumber daya, kemampuan dan strategi. Untuk mengisi gap antara inovasi pemasaran dan kinerja pemasaran maka dikembangkan konsep keunggulan produk iconic isolating. .

\section{Keunggulan Produk Iconic isolating}

Produk Ikonik, merupakan derivasi dari dimensi simbolis yang mempunyai kekuatan pasar yang berasal dari simbol budaya setempat yang terkenal dan tahan lama. Penggunaan simbolis pada produk ikonik banyak digunakan untuk membangun koneksi dan status sosial (Soroka dan Lominadze, 2011). Indonesia dengan berbagai latar belakang multietnis dan multi budaya, dapat mengembangkan produk dari interaksi anggota masyarakat multi etnis dan multikultural tersebut sehingga sebuah produk memiliki kesempatan untuk memilih unsur budaya asing dan budaya domestik tertentu sebagai ikon daerah asal (Ferdinand dan Fitriani, 2016).

Berbasis Resources Based View (Barney,1991), mekanisme isolating bagian dari strategik asset dan mekanisme isolating telah dikembangkan dalam literatur sebagai konstruksi intelektual untuk menjelaskan hambatan kompetitif di tingkat perusahaan individual. Mekanisme isolating didefinisikan sebagai fitur istimewa dari manajemen perusahaan untuk menciptakan hambatan untuk menghalangi pesaing meniru sumber daya, kemampuan dan strategi. Studi ini mengidentifikasi dua jenis mekanisme pengisolasian, kompetitif dan mekanisme pengisolasian berbasis pelanggan (Li dan Tsai, 2010) dan (Ferdinand dan
Lumban Batu, 2013). Keunggulan produk iconic isolating merupakan tingkat keaktifan suatu atribut produk yang mempunyai kekekuatan simbolis budaya setempat yang punya nilai berbeda dan susah untuk ditiru.

$\mathrm{H}_{1}$ : Inovasi pemasaran berpengaruh positif terhadap keunggulan produk iconic isolating

Inovasi merupakan kemampuan organisasi untuk mengadopsi dan mengimplementasikan baik ide baru, proses dan produknya. Kombinasi dari sumberdaya dan organisasi perusahaan menciptakan strategi inovasi bagi perusahaan yang mempengaruhi keunggulan bersaing terhadap kompetitor dan kinerja perusahaan. Studi (Waranantakul, dkk 2009) menghasilkan kapabilitas inovasi berpengaruh positif signifikan terhadap keunggulan bersaing. Penelitian (Chailom dan Ketchen, 2010) kapabilitas inovasi berpengaruh positif terhadap keunggulan bersaing perusahaan. beberapa studi juga mendukung hipotesis ini yaitu (Lee dan Hsieh, 2010).

$\mathrm{H}_{2}$ : Keunggulan produk iconic siolating berpengaruh positif terhadap kinerja Pemasaran

Keunggulan produk merupakan superioritas produk yang berbeda dengan pesaing . Studi (McNally 2010) bahwa keunggulan inovasi produk berpengaruh signifikan terhadap kinerja bisnis. Dalam proses perancangan produk, perusahaan ini berusaha menciptakan apapun yang menarik tetntang produknya, menghasilkan semacam atribut ikonik yang memiliki potensi untuk menarik konsumen potensial. Ferdinand dan Fitriani (2015) dengan daya tarik produk ikonik akulturatif mampu mempengaruhi kinerja pemasaran. Hsieh, dkk 2008; Leonidou (2011) keunggulan produk dengan nilai inovasi melalui desain produk, atribut lainnya serta kualitas produk mampu meningkatkan kinerja perusahaan.

$\mathrm{H}_{3}$ : Inovasi pemasaran berpengaruh positif terhadap kinerja pemasaran

Perubahan strategi pemasaran sebagai elemen penting dalam suksesnya (Moreira, $d k k$ 2012). (Avlonitis dan Salavou, (2007) 
menyatakan bahwa inovasi produk dengankeunikan dan kebaruananya pada UKM berpengaruh positif dan signifikan terhadap kinerja perusahaan. Hasil (Muangkhot dan Ussahawanitchakit 2014) pada indikator semua dimensi inovasi pemasaran memberi efek yang berbeda pada orientasi pembelajaran, kinerja entrepreneur dan strategi inovasi $R \& D$ berpengaruh positif pada kinerja produk baru

\section{METODE}

Jumlah perajin UKM Sarung Samarinda menurut data BPS ada sekitar 300 perajin. Daerah penelitian adalah di kampung tenun di Samarinda Seberang, sebagai populasi. Teknik sampel menggunakan sensus. Dan evaluasi akhir kuesioner, setelah dikurangi data oulier maka data yang bisa dianalisis adalah 235. Dan data dianalisis dengan SEM program AMOS

Indikator inovasi pemasaran yaitu terbuka terhadap ide baru, memperbaiki penampilan produk, mengembangkan peluang bisnis, mengembangkan pembaharuan produk (Hendar, dkk 2017). Indikator untuk keunggulan produk iconic isolating keunggulan motif ikonik, keunggulan corak ikonik, keunggulan design simbol, keunggulan atribut unik Ferdinand dan Fitriani, 2015). Sedang indikator kinerja pemasaran pertumbuhan volume penjualan, petumbuhan pendapatam penjualan, pertumbuhan tingkat pelanggan, pertumbuhan area penjualan (Avlonitis and Salavou , 2007)

Tabel. 1 Scale \& Measurement - Construct Validity

\begin{tabular}{lcc}
\hline \multicolumn{1}{c}{ Indikator } & $\begin{array}{r}\text { Standart } \\
\text { Loadings }\end{array}$ & $\boldsymbol{\alpha}$ \\
\hline Inovasi Pemasaran : & & \\
- Keterbukaan terhadap ide baru & 0.73 & \\
- Perbaikan tampilan produk & 0.79 & $\mathbf{0 . 8 3}$ \\
- Pengembangan peluang bisnis & 0.75 & \\
- Pengembangan pembaharuan produk & 0.75 & \\
\hline Keunggulan produk iconic isolating : & & \\
- Keunggulan motif ikonik & 0.68 & $\mathbf{0 . 7 5}$ \\
- Keunggulan corak ikonik & 0.70 & \\
- Keunggulan desain ikonik & 0.65 & \\
- Keunggulan atribut ikonik & 0.62 & \\
\hline
\end{tabular}

\begin{tabular}{lcc}
\hline \multicolumn{1}{c}{ Indikator } & $\begin{array}{c}\text { Standart } \\
\text { Loadings }\end{array}$ & $\boldsymbol{\alpha}$ \\
\hline Kinerja Pemasaran: & & \\
- Pertumbuhan volume penjualan & 0.73 & \\
- Pertumbuhan pendapatan penjualan & 0.80 & $\mathbf{0 . 8 5}$ \\
- Total pertumbuhan pelanggan & 0.78 & \\
- Tingkat area baru untuk penjualan & 0.76 &
\end{tabular}

$\mathrm{X}^{2}=60,380 ;$ Probability $=0.173, \mathrm{GFI}=0.959, \mathrm{AGFI}=0.938, \mathrm{TLI}=$ Sumber : data diolah

\section{HASIL DAN PEMBAHASAN \\ Hasil}

Kontruk reliabilitas memperlihatkan coeffisient cronbach alpha $(\alpha)$ dengan nilai di atas 0,7 dan nilai loading factor semua indikator berada di atas 0,6 menurut Ghozali (2013) indikator layak untuk dipakai. .

Hasil statistik memperlihatkan inovasi pemasaran and keunggulan produk iconic isolating berpengaruh positif and signifikan terhadap keunggulan produk iconic isolating. Inovasi pemasaran berpengaruh positif and signifikan terhadap kinerja pemasaran. Semua variabel menunjukkan instrument nilai validitas baik. Hasil statistikal dipresentasikan pada Tabel 2 berikut:

Tabel 2 Regression Weigth

\begin{tabular}{|c|c|c|c|c|c|}
\hline & Estimate & S.E. & C.R. & $P$ & Label \\
\hline $\begin{array}{l}\text { Inovasi } \\
\text { Pemasaran } \rightarrow\end{array}$ & & & & & \\
\hline $\begin{array}{l}\text { Keunggulan } \\
\text { Produk Iconic } \\
\text { isolating }\end{array}$ & 0.508 & 0.073 & 6,998 & $* * *$ & Significant \\
\hline $\begin{array}{l}\text { Keunggulan } \\
\text { produk Iconic } \\
\text { is olating } \rightarrow\end{array}$ & 0.832 & 0.146 & 5,695 & $* * *$ & Significant \\
\hline $\begin{array}{l}\text { Kinerja } \\
\text { Pemasaran }\end{array}$ & & & & & \\
\hline $\begin{array}{l}\text { Inovasi } \\
\text { Pemasaran } \rightarrow\end{array}$ & & & & & \\
\hline $\begin{array}{l}\text { Kinerja } \\
\text { pemasaran }\end{array}$ & 0.202 & 0.092 & 2,205 & 0.027 & Significant \\
\hline
\end{tabular}

Sumber : data diolah 
Hasil statistik tergambar full model dengan AMOS sebagai berikut :

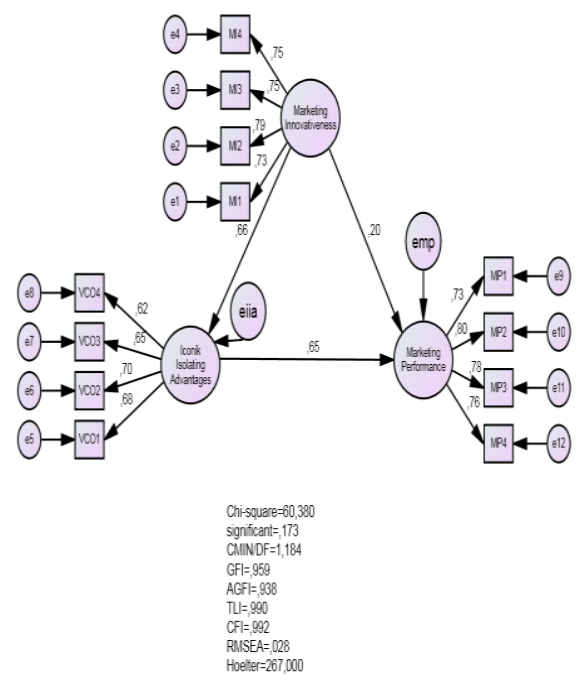

Gambar 1. Full Model

Pengukuran model menggunakan AMOS 20 dengan maximum likelihood, hasil statistik dengan model fit yaitu Chi-square $=$ 60.380 , probability $=0.173$, GFI $=0.959$, AGFI $=0.938, \mathrm{TLI}=0.990, \mathrm{CFI}=0.992$, RMSEA $=0.28$.

Analisis multi-items diestimasi dengan factor loading dan cronsbach alphas. Hasil loading faktor positif and signifikan dengan nilai factor loading $(\mathrm{p} \leq .05)$ Cronsbach alphas dari.0.75 hingga .0.85. Dengan di dukung hasil sobel tes dimana sobel tes 4,408 dan signifikan adalah 0,00 dibawah 0,05 maka disimpulkan bahwa keunggulan produk iconic isolating mampu sebagai pemediasi antara inovasi pemasaran dan kinerja pemasaran.

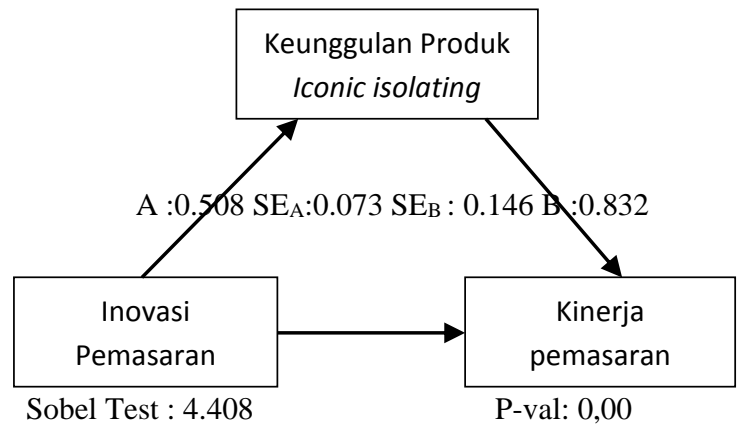

Gambar 2. Hasil Uji Sobel Tes

\section{Pembahasan}

Studi ini menemukan penemuan yang menarik yang saling melengkapi antara pemasaran inovasi terhadap keunggulan produk iconic isolating dan kinerja pemasaran. Khususnya dengan teori Resources Based View yang memberi pengaruh komplementari (Morgan, 2012). Sebuah pandangan bahwa kemampuan bisnis untuk mengembangkan dan menyebarkan beberapa kemampuan internal terutama kemampuan inovasi untuk pertumbuhan perusahaan yang berkelanjutan.

Hasil penelitian ini menegaskan argumen bahwa inovasi pemasaran merupakan konsekuensi dari pencapaian kinerja dan membuktikan bahwa inovasi pemasaran yang ditunjukkan oleh tingkat keterbukaan gagasan baru, perbaikan penampilan produk, pengembangan peluang bisnis, pengembangan pembaharuan produk (Hendar, et. al 2017) dapat meningkatkan kinerja pemasaran. Kreativitas pemasaran lebih lanjut juga memiliki efek positif yang signifikan terhadap penciptaan nilai ikonik, yang memiliki arti bahwa semakin tinggi perusahaan di industri UKM meningkatkan inovasi pemasaran mereka, maka keunggulan produk iconic isolating nilai akan meningkat.

Kontribusi studi ini adalah dalam menentukan komponen kunci dari inovasi pemasaran yang membangun nilai keunggulan produk iconic isolating yang harus dikembangkan dan dijalankan oleh para pengusaha secara strategis untuk melakukan penciptaan nilai keunggulan produk iconic isolating. Komponen dari nilai tersebut menunjukkan bahwa konseptualisasi dan ukuran yang valid menentukan di mana sebuah perusahaan yang bergerak dalam bidang usaha untuk mengembangkan secara strategis nilai kuncinya yang ikonik adalah dengan mengembangkan design ikonik, motif, symbol ikonik, pengalaman pembuatan produk ikonik (Ferdinand dan Fitriani 2015)

Temuan ini memberikan dukungan kuat untuk pentingnya kemampuan inovasi pemasaran dan keunggulan produk iconic isolating dalam meningkatkan kinerja 
pemasaran yang dibuktikan memiliki efek positif yang signifikan. Di sisi lain, hasil penelitian ini menegaskan pentingnya penciptaan keunggulan produk iconic isolating sebagai aspek penting dari kinerja pemasaran.

Hasil penelitian ini memberikan dua alternatif yang mungkin dilakukan oleh pemilik usaha kecil dan menengah di industri kerajinan tangan UKM di Indonesia yang pertama, mengelola inovasi pemasaran dengan keterbukaan gagasan baru, memperbaiki penampilan produk, mengembangkan peluang bisnis, mengembangkan produk. pembaharuan. Dengan meningkatkan inovasi pemasaran dapat meningkatkan kinerja pemasaran. Alternatif kedua adalah dengan menggunakan pendekatan keunggulan produk iconic isolating untuk mencapai kinerja pemasaran yang tinggi. Pemilik dapat mengatur kreasi keunggulan ikonik isloating dengan meningkatkan keunggulan motif iconic isolating, corak iconic isolating dan atribut iconic isolating . Keunggulan produk iconic isolating terjadi saat inovasi pemasaran dijalankan.

\section{Kesimpulan}

Makalah ini memiliki tujuan akhir untuk mendeskripsikan pengaruh inovasi pemasaran yang mengukuhkan proses keunggulan produk iconic isolating dalam konteks UKM. Penelitian ini memberikan kontribusi dan memberikan bukti baru terhadap literatur mengenai keunggulan produk iconic isolating dan inovasi pemasaran ikonik. Studi ini meningkatkan pemahaman alat inovasi yang dapat digunakan untuk memudahkan proses meningkatkan keunggulan produk iconic isolating sebagai cara pengusaa pasar setempat untuk membuat produk yang khas regionsentris.

Hasil penelitian ini menunjukkan peran penting dari keunggulan produk iconic isolating dalam menjembatani kesenjangan antara inovasi pemasaran dan kinerja pemasaran. Meski ada hasil penelitian yang mengklaim bahwa ada kontradiksi antara inovasi pemasaran dan kinerja pemasaran oleh (Hoonsopon dan Ruenroom, 2012), hasil kontradiksi ini diakhiri dengan pernyataan yang jelas bahwa keunggulan produk iconic isolating mampu menengahi kesenjangan antara inovasi pemasaran dan kinerja pemasaran yang dibuktikan dari hasil sobel tes, dimana keunggulan produk iconic isolating mampu memediasi antara pemasaran inovasi dan kinerja pemasaran.

Untuk memenangkan persaingan usaha global, industri kerajinan tangan Sarung Samarinda UKM Kalimantan Timur harus dapat berinovasi dan dalam rangka meningkatkan kinerja pemasaran. UKM Sarung Samarinda harus bisa terus menghidupkan keunggulan produk iconic isolating agar kerajinan khas Kalimatan Timur tidak mudah lenyap dan bisa bertahan. Tentunya lebih baik bila UKM Sarung Samarinda juga mampu membuat label sendiri untuk mempermudah konsumen dalam mengidentifikasi produk dari Sarung Samarinda yang ada di pasaran.

\section{DAFTAR PUSTAKA.}

Atalaya, M., Anafarta, N. and Sarvanc, F. (2013), "The relationship between innovation and firm performance: An empirical evidence from Turkish automotive supplier industry", Procedia - Social and Behavioral Sciences, Vol. 75, 3 April 2013, pp. 226-235.

Atuahene-Gima, Kwaku., Li, Haiyang.,De Luca, Luigi.M, (2006) " The contingent value of marketing strategy innovativeness for product development performance in Chinese new technology ventures, Industrial Marketing Management 35 359-372

Avlonitis , G. J., and Salavou, H. E. (2007). Entrepreneurial orientation of SMEs, product innovativeness, and performance. Journal of Business Research 60: 566-575. 
Al-Zyadaat, M.A., Saudi, M.A. and AlAwamreh, M.A. (2012), "The relationship between innovation and marketing performance in business organizations: An empirical study on industrial organizations in the industrial city of King Abdullah II", International Business and Management, Vol. 5, No. 2, pp. 76-84.

Barney, J (1991) Resources and Sustained Competitive Advantage, Journal of Management, p. 99-120

Carbonell, P. and Escudero, A.I.R.G. (2010), "The effect of market orientation on innovation speed and new product performance", Journal of Business \& Industrial Marketing, Vol. 25, No. 7, pp. 501-513.

Cillo A.P., De Luca, L.M and Troiloa, G (2010) Market information approaches, product innovativeness, and firm performance : An empirical study in the fashion industry. Research Policy., $39,1242-1252$.

Darmanto, Darmanto., Running, Hunik Sri., Harsono, Mugi.,Haryono, Tulus (2014)"The Relationship between Strategy Orientation and Marketing Performance: The Role of Organizational Change Capability", American International Journal of Contemporary Research, Vol. 4, No. 1

Ferdinand, Augusty Tae dan Lumban Batu, Kardison (2013), MaIsCap-Marketing Architectural Isolating Capability as antecedents for s uccess of new produst development, Journal of Economics, Business, and Accountancy Ventura Volume 16, No. 3, December 2013, hlm. 487 - 502 Accreditation No. 80/DIKTI/Kep/2012

Ferdinand, Augusti Tae and Fitriani, Lili Karmela (2015)' " Acculturative Iconic product Attractiveness and Marketing performance", Journal of Global Strategic Management, Vol. 9, No. 2, pp. $15-23$

Ghozali., I (2013) Konsep dan Aplikasi dengan AMOS 20, Semarang : BP Undip

Hair, J.F., Black, W.C., Babin, B.J. and Anderson, R.E. (2010), Multivariate data analysis, 7 Ed., Prentice Hall, New York.

Hendar,Hendar., Ferdinand, Augusti Tae ., Nurhayati, Tatiek, " Introducing the religio-centric positional advantage to Indonesian small businesses ",Management \& Marketing. Challenges for the Knowledge Society, Vol. 12, No. 1, pp. 78-102.

Hoonsopon, D. and Ruenrom, G. (2012), "The impact of organizational capabilities on the th development of radical and incremental product innovation and product innovation performance", Journal of Managerial Issues, Vol. 24, No. 3, pp. 250276.

Hsieh, M.H.,K.H Tsai dan J.R Wang (2008) " The Moderating effect of market orientation and launch profisiency on the product advantage - performance relationship ", Industrial Marketing Management, Vol. 37, hlm. 580 - 592

Karabulut, A.T. (2015), "Effects of innovation types on performance of manufacturing firms in Turkey", Procedia - Social and Behavioral Sciences, Vol. 195, 3 July 2015, pp. 1355-1364.

Lee, J.S dan C.J Hsieh (2010) A reseach in relating entrepreneurship, marketing capability, innovative capability, and sustained competitive advantage a " Journal of Business and Economic Reseach, Vol. 8, No.9 
Leonidou, L.C., Palihawadana. P. dan Theodosiou. M (2011) National export-promotion programs as drivers of organizational resource and capabilities : effect on strategy, competitive advantage and performance, Journal of International marketing, Vol. 19, No. 2, hlm: 1-29

Li, Yi-Pei dan Tsai, Yuh-Yuan (2010) The study of isolating mechanisms as firm's sustainable competitive advantages

Mc-Nally, R.C., Casvugil, E dan Calantone R.J (2010) Product Innovativeness dimensions and their relationships with product advantage, product financial performance and project protocol, Journal product Innovations management, Vol. 27., hlm. 991-1006

Moreira, J., Silva, M.J., Simões, J. and Sousa, G. (2012), "Drivers of marketing innovation in Portuguese firms", Amfiteatru Economic, Vol. 14, No. 31, pp. 195-206.

Rosli, M.M. and Sidek, S. (2013), "The Impact of Innovation on the Performance of Small and Medium Manufacturing Enterprises: Evidence from Malaysia", Journal of Innovation Management in Small \& Medium Enterprise, Vol. 2013 No. 2013, pp. 116.
Soroka, Ekaterina and Lominadze, Tea (2011), "Branding destination through iconic product ", Thesis, Lunds Universitet

Waranantakul, O.P, Ussahawanichat dan Jhundra-indra P (2009) Service innovation creation capability of spa business in Thailand : an emprirical investigation of the antecedents and concequences

Yalcinkaya. G., Calantone., R.J and Griffith, D.A (2007) "An Examination of exploration and exploitation capabilities : Implications for product innovation and market performance, Journal of International Marketing., 15 (4), pp. 6-93 